\title{
Glu89Gln transthyretin-related amyloidosis in Italy and Bulgaria: does geographic area influence phenotype beyond the shared mutation?
}

\author{
Christian Gagliardi ${ }^{1 *}$, Mariana Gospodinova ${ }^{2}$, Simone Longhi ${ }^{1}$, Agnese Milandri ${ }^{1}$, Mario Cinelli ${ }^{1}$, Ivailo Tournev ${ }^{3}$, \\ Fabrizio Salvi ${ }^{4}$, Claudio Rapezzi ${ }^{1}$
}

From First European Congress on Hereditary ATTR amyloidosis

Paris, France. 2-3 November 2015

\section{Background}

Glu89Gln transthyretin (TTR) variant is a well-known cause of systemic amyloidosis with a cardiologic, neurologic or mixed phenotype. Even though Glu89Gln transthyretin (TTR) variant has been described worldwide, it remains unknown whether geographical area influences the phenotypic expression of the disease (as happens with the Val30Met mutation, which is known to manifest with different phenotypes in different geographical contexts). We hypothesized that significant phenotypic differences exist between patients with Glu89Gln-related amyloidosis according to the specific geographic origin.

\section{Methods}

We retrospectively analysed and compared the clinical, electrocardiographic and echocardiographic findings of 64 patients with Glu89Gln TTR-related amyloidosis from Italy and Bulgaria.

\section{Results}

Despite a similar age at diagnosis of the disease (55 [52-60] years) patients in Bulgarian cohort have a mixed phenotype. A more severe left ventricular wall thickening was present in Bulgarian cohort compared to Italian one (17 [16-18] $\mathrm{mm}$ vs 15 [13-16], $\mathrm{p}=0.009)$ with a normal ejection fraction in all cases.

\section{Conclusion}

This is the largest series so far of patients with Glu89Gln TTR-related amyloidosis systematically analysed. Overall, disease onset is late with a mixed phenotypic expression.

Diagnostic and Specialty Medicine - DIMES, Alma Mater Studiorum,

University of Bologna, Cardiology, 40138, Bologna, Italy

Full list of author information is available at the end of the article
Despite a similar age at onset and a predominance of neurological routes, Bulgarian patients showed a more pronounced cardiomyopathy.

\section{Authors' details}

'Diagnostic and Specialty Medicine - DIMES, Alma Mater Studiorum, University of Bologna, Cardiology, 40138, Bologna, Italy. ${ }^{2}$ University Hospital Alexandrovska, Clinic of Cardiology, 1000, Sofia, Bulgaria. ${ }^{3}$ University Hospital Alexandrovska, Clinic of Neurology, 1000, Sofia, Bulgaria. ${ }^{4}$ Bellaria Hospital, Neurology, 40100, Bologna, Italy.

Published: 2 November 2015

\section{doi:10.1186/1750-1172-10-S1-P23}

Cite this article as: Gagliardi et al:: Glu89GIn transthyretin-related amyloidosis in Italy and Bulgaria: does geographic area influence phenotype beyond the shared mutation? Orphanet Journal of Rare Diseases 2015 10(Suppl 1):P23
Submit your next manuscript to BioMed Central and take full advantage of:

- Convenient online submission

- Thorough peer review

- No space constraints or color figure charges

- Immediate publication on acceptance

- Inclusion in PubMed, CAS, Scopus and Google Scholar

- Research which is freely available for redistribution

Submit your manuscript at www.biomedcentral.com/submit 